\title{
SOLUTIONS TO ISSUES DEPEND ON THE KNOWLEDGE REPRESENTATION
}

\author{
Frederick B. Thompson \\ californig Institute of Technology \\ Pasadena, Callfornill
}

In organizing this panel, our

Chairman, Eob Moore, expressed the view that too of ten discussion of naturil language access to data bases has focused on what particular systems cin or cannot do, rather than on underlying issues. He then admirably proceeded to organize tha panel around issues rather than systems. In responding, I attempted to frame my remarks on erch of his five issues in a general way that would not reflect my nwn parochiol experience and interest. At one point I thought that I had succesded qujte we11. However, after taking a clearer eyed view, it was apparent that ay ramarks reflected assumptions about knowledge representation that were by no means uni versol. This suggests a sixth issue which I would like to numinnte:

Are there really useful generalizations about computational linguistic issues that are independent of rassumptions concerning knowledgu representation?

I will come back to this sixth issue after discussing the five chosen by our chairmors.

\section{Isste *i: Aogreagte Functions and Quantity Questions}

First, let us cast this issue in a somelwhat different way. In many data base stuations, there are classs of individuals nll of whuse members share the ane atiributes and thus, fram the point of vinw of the data base, rar

indistingujshable. Thus there is no need to add rill of these individuals as

separde entitjes. To use kab Moore's example, if a DEPARTMENT file lias a $f$ ield for NUMEER - OF-EMPLOYEES, it stands to ratson that the particular individuals who neturliy existed in the various deprartments would not be saparately represpred in the database ffor otherwise there would be a redundancy whose

angjetchey would be hard to police). In such situakions we need the notion of a "-ollecti"se:" namely a single data base object that lakes the place of a number of indiydugis and which can carpy thejer common atreributes together with one ndditiondl. item of information, namely their number. Thus a DEPARTMENT coujd have as a single member surh a collective of employees, indeed it could have several such collective members and other

individual members as well. The procedure that is called when answering "how many" and "number of" questions would know the difference between subclasses, individual members and collective members; it would know to pecurse on subclasses, ard one to its count for indiuidual members and add the indicated number to its count for collectjue members. This appents to be a unified framework that will handle all of the cases mentioned in Eob Moore's statement of Is sue +1 .

\section{Issue 2: Time and Tense}

I should like to split this issue into two. The first sub-issue is the problem of handing continously uarying phenomena, such as the movement of ships, the changing of relatiug amounts of inaredients in chemical reactions, or the percent cumpletions of tasks. Here it is apparent that each instance will require a speciallzed procedure to handle interpolatian. Ships cannot sail across land, thus an interpolation procedore that produces the position of a ship on the basis of its puints of depreture ond destingtion wil.j. nesd to know about the coastlines of continents; movements to chemjcal equiljoriums are not linear; task completions depend on changing personnel. ossignments. Just as we computational linguists proulde to our systen user the capability to introduce into his data base system such notions as locations of ports and ships, etc, we must also proujde the means by whith he can dafine such continuously varying parameters as position in such wrys that appropriate interpojations can be made by the general system in conjunction with the particular definition. For example, the user may Jefine: "position of $x$ " in terms of calculations, perhaps extensive, involping the retual geometry of the 
The second sub-issue on which I would 1.ike to comment cuncerns those cases where discrete time intervals provide an adequate representation of the time aspects relevant to the data base. In these coses, if the time information is complete, i.e., actual starting and endjing times of all eyents are recorded in the data base, the handiling of time is rather straj.ghtforward. However this case often does not apply. Conslder the following exampla:

"The Kittyhawk arrived in London Monday, The Maru will sail from London Friday. Will the Kittyliawk and Maru have been in Londion at the same time?"

Ons is tenpted to allow the computer to give a response: "Possibly," however the introduction of a three valued logic is fraught with well known dangers of $i t s$ uwn. A more protracted response gets in the wry of clnuse imbedding: how does one riandle:

"Will ships that have been in London rogether sail together?"

One answer would be:

"The Kitruhawk arrived last Monday: the Mary will sail next Friday. If they will have buen there at the same time, then not all ships that were in London together will snil together, but they would be the only exceptions."

Choosing a relevant diagnosti. messoge, as above, is a major and difficult computational aiquistic issue going we li beyound questjons concerning time and tinse.

\section{Issue H: Quantifuing into Questions}

This is a deep, philosophiral question. Computational linguists have prograssed beyond thr considerntion of single sentences, and are seeking to follow the focus of a dicloqut and iclentify the theme of a discourse. This is

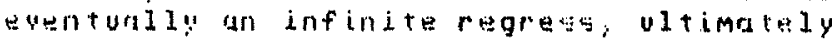
ingoluding cross cultural backgrounds, the cperhaps Machituyelidan? intent of those who control the use of a particular application; atc. but the enginesering problen. at ledst at the present state of the art, is simple: what response is Most useful to the user" Consjder two possjble answers to the following question

"Who manages etich department?"
A1: "Nu single person manages all of the departments."

A2: "department manager dept. A manager A ,..

Unless there were an undue number of departments involued, the sei:ond is c.learly preferred, for it suffices even if the first were intended. In our own experience, "each" can usefully be interpreted as calling for a labeled list is answer in nlmost all cases. The difficulides of beine more cleuer are great and will often result in a combinatorial explosion. I am surs, for a Jong tjMe into the future, we will be seeking simple solutions that (a) are responsive in most cases, (b) provide the needed information, wen though redundant in some case, and (c) make clear the misinterpretation in the few case where this arjses, even though these solutions may violate strict linguistic anrlysis.

Issue 4 : Querying semantically Camplex Fields

In presenting this issue to the panel, Bob Hoore used the following thres questions as an example:

\footnotetext{
"Is John Jones a rhLld of an MIT alumnus?"

"Is one of John Jones's parents an MIT alunnus?"

"Did sillier parent of John Jones attend MIT?"
}

The apunreit problem is the possibility of multiple descriptions, often involving disparate words, for getting at data in the data base, In designillg our systems, we recognize two truths which apperir to tonflict: (a) the value of minimizing the redundancy of information in the data bises. (b) the necessily of non-independent words in the vocabulary. In our own work, as must of you knuw, we have stressed the use of لyefinitionis as a melas of achjeving a aynthesis of these two principles. I recommend it to you as a vary usioful tool in handiling problems like kob presents. We illustrate how Bob's example tan bo handledi

\footnotetext{
"definition:child:converse of parent verb:John "attend"s NITIJohm is a sudent of MIT

definjtion:alugi sperson who had been a student"
} 
The sbove three questions then are andized as:

"John Jones is (converse of parent) of a person who had been a student of MIT?"

"One of John Junes's parents is a person who had been a student of MIT?"

"Was elither parent of John Jones a student of MIT?"

I do not wish to slur over the fact that a definition mechanism must be highly sophisticated in its handling of free variables; but our experience indicates that thjs can be done quite satisfactorily.

Issue 5 : Multi-File Queries

This issue has been stated by Bob in rerms of a traditional multiple file data base struture. This issue has its counterpart in semantic net datr base structures discussed in papercis on knowledge representation. Since we use such a semantic net structure for our data, let me rephrase the issue in those terms. In Eob's statement of the issue, he uses the example of the SHIP file and the PORT file: where the SHIP file has fields for home port, departure port and destinution port. Prarallejing his axample, let us consider the phrase: "Londun ship". Suppuse that (a) there bag a ship llamed Landon, and (b) London was a home port, port of departure and destingtion, not necessarily of the same ship. Then "London ship" is four wrys ambiguous, meaning: (1) the ship London, (2) London (home port) ships, (3) London (departure port) ships and (4) Landon (destination port) ships. In this rormulation of the problem, all is easy; insofar as the phrist "loondon ship" is not disambiguated in context, the user is informed of the ambiquous minuings and the assaciated responses. The difficulty ar ises when there are possibile interpretations farther afield. Fort Collins is neither if port nor a ship, however the headquarters of the Aac shipping comprany is there and they own several. ships. What are we 10 mean by "Fort Collins ship"? Thesse rars problems that were first attacked by Quilidan, and I am not sure that anyone has added to his weminal andysig of them. In our own work, we have glopped at "once renoved" connections, as illustrated by the four wry ambigulty abous.
Issue 6: Solutions to Issues Depend on knowledar Representation

As I look back on the abuve remark roncerning Bob's fiue issues, it becomes apparent that the usefulness of these remarks depends on the degree one is aware of the knowledge representation thit underlifes the solution suggested. For example, in the case of the last isgue, if one only knew about traditional file structures, finding paths thit link fields in more than one file appears all but unsolvable. Even if one is accustumed to Eemantic net structures, the viability of flnding connective paths is highly dependent on the existence of back links between attributes and their rirguments and yalues. Adding a definitional capability, other than simple abbreviations and synonyas, turns on the way free yariables are handled in general and on that apparatus for binding them; for example, in processing the definition:

"definition:area:length times width"

when applied to " class, say "rous of ships", low does one ensure that he will obrain:

"length(i) * width(i)

for $i=1$ to number of shipe"

rother thon:

"Iength(i) * width(j)

for $i, j=1$ to llumber of ships?"

It comes down to how yariables are maintained in the underlying knowledge representation.

One is forced to conclude that the basis for the integration of tha syntax and semontics of computational linguistic systems is accomplished whon the decisions on knowledoe representation are made, Discussions of our variaus solutinn to the issues of computational linguistics can meaningfully take place only in terms of these underlying knowledge representations. 